(c) American Dairy Science Association, 2005.

\title{
Effects of Sterilization, Packaging, and Storage on Vitamin C Degradation, Protein Denaturation, and Glycation in Fortified Milks
}

\author{
H. Gliguem and I. Birlouez-Aragon \\ Institut National Agronomique Paris-Grignon, Laboratoire de Chimie Analytique, \\ 16 rue Claude Bernard, 75231 Paris, France
}

\begin{abstract}
Monitoring the nutritional quality of dietetic milk throughout its shelf life is particularly important due to the high susceptibility of some vitamins to oxidation, and the continuous development of the Maillard reaction during storage.

The objective of this paper was to evaluate the vitamin $\mathrm{C}$ content and protein modification by denaturation and glycation on fortified milk samples (growth milks) destined for 1- to 3-yr-old children. The influences of the sterilization process, formulation, packaging, and storage duration at ambient temperature in the dark were studied. Vitamin C degradation was particularly influenced by type of packaging. The use of a 3-layered opaque bottle was associated with complete oxidation of vitamin $\mathrm{C}$ after 1 mo of storage, whereas in the 6layered opaque bottle, which has an oxygen barrier, the vitamin C content slowly decreased to reach $25 \%$ of the initial concentration after 4 mo of storage. However, no significant effect of vitamin $\mathrm{C}$ degradation during storage could be observed in terms of Maillard reaction, despite the fact that a probable impact occurred during sterilization. Furosine content and the FAST (fluorescence of advanced Maillard products and soluble tryptophan) index-indicators of the early and advanced Maillard reaction, respectively-were significantly higher in the in-bottle sterilized milk samples compared with UHT samples, and in fortified milk samples compared with cow milk. However, after 1 mo, the impact of storage was predominant, increasing the furosine level and the FAST index at similar levels for the differently processed samples. The early Maillard reaction developed continuously throughout the storage period.

In conclusion, only packaging comprising an oxygen and light barrier is compatible with vitamin $\mathrm{C}$ fortification of milk. Furthermore, short storage time or low storage temperature is needed to retard vitamin $\mathrm{C}$ deg-
\end{abstract}

Received April 22, 2004.

Accepted November 17, 2004.

Corresponding author: Inès Birlouez-Aragon; e-mail: birlouez@ inapg.fr. radation, protein denaturation, and development of the Maillard reaction.

(Key words: fortified milk, storage, vitamin C, Maillard reaction)

Abbreviation key: CM-St-3L = cows' milk, in-bottle sterilized, stored in 3-layered packaging, CM-St-6L = cows' milk, in-bottle sterilized, stored in 6-layered packaging, FAST = fluorescence of advanced Maillard products and soluble tryptophan, FM-St-3L = fortified milk, in-bottle sterilized, stored in 3-layered packaging, FMSt-6L = fortified milk, in-bottle sterilized, stored in 6layered packaging, FM-UHT-3L = fortified milk, UHT sterilized, stored in 3-layered packaging, FM-UHT$\mathbf{6 L}=$ fortified milk, UHT sterilized, stored in 6-layered packaging.

\section{INTRODUCTION}

Sterilization allows prolonged shelf life of milk-up to 6 mo for UHT milk and up to 12 mo for in-bottle sterilized milk. Although it is often considered that a food product is generally stable throughout its shelf life, numerous studies indicate that oxidation (Almaas et al., 1997), hydrolysis (Richards and Chandrasekhara, 1960; Alkanhal, 2000), and glycation (Corzo et al., 1994; Albala-Hurtado et al., 1999; Ferrer et al., 2000a) reactions develop during storage at ambient temperature. The quality of packaging, especially its permeability to atmospheric oxygen, proves to be very important, especially for foods fortified with compounds prone to oxidation, such as essential fatty acids and vitamins (C, $\mathrm{B}_{2}$, and $\mathrm{B}_{9}$ ) (Reddy and Love, 1999), as is the case for fortified milk formulas.

There are primarily 2 types of packaging used for liquid milks: 6-layered Tetra-Pak packaging, and 3- or 6-layered polyethylene bottle packaging. The presence of an oxygen barrier in 6-layer packaging seems more adapted to the storage of foods fortified with oxidationprone nutrients.

Heat sterilization of milk is essential to ensure total microbiological safety and enzymatic stability. However, it is clear that a sterilized milk sample is not physico-chemically stable, as many reactions develop 
that are initiated during the sterilization process. Protein denaturation specifically concerns whey proteins and is considered to improve protein digestibility and decrease their allergenic properties (Korhonen et al., 1998). But other reactions, such as the Maillard reaction, lead to a decrease in the nutritional value of proteins and a modification of the organoleptic properties of milk (cooked taste and browning). The specific composition of fortified formulas explains their high susceptibility to formation of Maillard products (Birlouez-Aragon et al., 1997; Evangelisti et al., 1999), specifically, the high lactose content, the presence of proteins with many reactive lysine residues (Finot et al., 1981), and the activation allowed by ferrous ions (Birlouez-Aragon et al., 1997).

The reactions described above are complicated by the addition of iron and vitamin $\mathrm{C}$ to the fortified milks (Almaas et al., 1997). The background of such a fortification is their nutritional interest [the need for $60 \mathrm{mg}$ vitamin $\mathrm{C}$ per day for 1- to 3-yr-old children, and prevention of iron deficiency (Hurrell, 1999)], and the facilitated iron absorption at the intestinal level (Gill et al., 1997; Lynch and Stoltzfus, 2003). Iron bioavailability is particularly low in milk ( 2 to $3 \%$ ) because of the high calcium concentration (Hallberg et al., 1992), but is multiplied 2-fold in the presence of vitamin C (Gillooly et al., 1984). However, the instability of vitamin C raises the question of the impact of the process and storage on fortified milks.

The problem of vitamin $\mathrm{C}$ oxidation during storage is solved by adding a compensating concentration before the process, such that the recommended level is still present at the end of the shelf life. However, the degradation of high amounts of vitamin $\mathrm{C}$ in milk could have some deleterious effects on other aspects of the nutritional quality (Birlouez-Aragon et al., 2004). In particular, the role of vitamin $\mathrm{C}$ degradation products on the development of the Maillard reaction (Leclère et al., 2002) and radical reactions initiated by the ironvitamin C mixture (Stadtman, 1991; Almaas et al., 1997) have been reported. The loss of protein digestibility (Rowley and Richardson, 1985; Jelen and Rattray, 1995), the decrease in the bioavailability of several essential amino acids (particularly lysine and tryptophan), and formation of undesirable compounds such as carboxymethyllysine (Birlouez-Aragon et al., 2004) could be explained by vitamin C-derived Maillard reaction (Leclère et al., 2002; Puscasu and Birlouez-Aragon, 2002).

Several useful indicators can be analyzed to characterize the consequence of heat treatment on the nutritional quality of heat-treated milks. The extent of whey protein denaturation can be evaluated by the determination of the $\mathrm{pH} 4.6$-soluble $\beta$-lactoglobulin content
Table 1. Milk composition according to labeling.

\begin{tabular}{lcl}
\hline For $100 \mathrm{~mL}$ & Fortified milk & Cows' milk \\
\hline Proteins $(\mathrm{g})$ & 2.6 & 3.2 \\
Lactose $(\mathrm{g})$ & 8 & 5 \\
Iron $(\mathrm{mg})$ & 1.30 & 0.04 \\
Vitamin C (mg) & 6 & 1.43 \\
Linolenic acid (mg) & 49 & $\mathrm{ND}^{1}$ \\
Linoleic acid (mg) & 396 & $\mathrm{ND}$ \\
\hline
\end{tabular}

${ }^{1} \mathrm{ND}=$ Not determined.

(Law and Leaver, 2000; Villamiel and de Jong, 2000). The lactulosyllysine is the main chemical form of lysine blockage by the Maillard reaction in heat-treated milk (Bujard and Finot, 1978; Finot et al., 1981; Rerat et al., 2002), with furosine being a good indicator of the lactulosyllysine content (Resmini and Pellegrino, 1991; Pizzoferrato et al., 1998; Evangelisti et al., 1999). The fluorescence of advanced Maillard products and soluble tryptophan (FAST) method (Birlouez-Aragon et al., 2002) seems well adapted to evaluate the extent of the Maillard reaction in complex media where substrates other than lactose (vitamin C, polyunsaturated fatty acids) are possible precursors of the reaction (Leclère et al., 2002; Birlouez-Aragon et al., 2004). Other indicators are available, such as lactulose (Nangpal and Reuter, 1990), carboxymethyllysine (Drusch et al., 1999; Kislinger et al., 2003), and hydroxymethylfurfural (Albala-Hurtado et al., 1997; Ferrer et al., 2000b), although they essentially give redundant information, as they are interrelated (Hewedy et al., 1994; Van Rentherghem and De Block, 1996).

Our objective in this study was to identify the respective roles of the sterilization process (UHT or in-bottle), packaging (3-or 6-layered polyethylene opaque bottles), formulation (fortified milk or cows' milk), and storage time ( $3 \mathrm{~d}$ to $4 \mathrm{mo}$ in the dark, at ambient temperature) on the vitamin $\mathrm{C}$ content. In addition, we evaluated some indicators of protein denaturation (native whey protein content and Trp fluorescence) and Maillard reaction (furosine, FAST index) in regular and fortified milk. The potential interactions between these process factors were determined.

\section{MATERIALS AND METHODS}

\section{Milk Samples}

Semi skimmed cows' milk samples and fortified milks (composition is given in Table 1) were provided by a French industrial dairy plant. They were manufactured from the same milk, formulated (in the case of fortified milk), and sterilized by 2 methods: indirect UHT and in-bottle sterilization. For each sample, 2 packaging materials were used: 3 - and 6-layered high density poly- 
ethylene opaque bottles, the latter containing an oxygen barrier (ethylene vinyl alcohol). The polyethylene permeability to oxygen (measured on a $1-\mu \mathrm{m}$ film at $23^{\circ} \mathrm{C}$ and $0 \% \mathrm{RH}$ ) is close to $50,000 \mathrm{~cm}^{3} \cdot \mu \mathrm{m} / \mathrm{m}^{2}$ per bar as compared with 4 to 60 for ethylene vinyl alcohol. The milk samples were stored at ambient temperature for 4 mo in the dark.

The following nomenclature for sterilization and storage methods was used: CM-St-3L and CM-St-6L: inbottle sterilized cows' milk $\left(110^{\circ} \mathrm{C}, 20 \mathrm{~min}\right)$, in 3 - and 6layered packaging, respectively; FM-UHT-3L and FMUHT-6L: UHT fortified milk ( $135^{\circ} \mathrm{C}, 3$ to $\left.4 \mathrm{~s}\right)$, in 3 - and 6-layered packaging, respectively; and FM-St-3L and FM-St-6L: in-bottle sterilized fortified milk in 3- and 6-layered packaging, respectively.

After each storage time ( $3 \mathrm{~d}, 1,2$, and $4 \mathrm{mo}), 3$ bottles of each milk sample were opened for analysis.

\section{Vitamin C Quantification}

One milliliter of milk sample was stabilized by addition of an equivalent volume of $10 \%$ metaphosphoric acid (Fluka, St. Quentin Fallavier, France) and centrifuged. Ascorbic acid was oxidized into dehydroascorbic acid with potassium ferricyanide (1 g/L) (Sigma, France), and derived by ortho-phenylene diamine according to the method of Tessier et al. (1996). The quinoxalic derivative was separated by HPLC (Hypersil column ODS C18, $25 \times 4.6 \mathrm{~mm}$ ) and detected by fluorescence $(360 / 440 \mathrm{~nm})$. All analyses were done in duplicate.

\section{Analysis of Soluble Whey Proteins}

Protein denaturation was indirectly quantified by precipitation of the unfolded proteins at $\mathrm{pH} 4.6$, whereas native proteins remained soluble at this $\mathrm{pH}$. The content of $\alpha$-lactalbumin and $\beta$-lactoglobulin of the $\mathrm{pH}$ 4.6-soluble protein fraction was quantified by HPLC. One hundred microliters of $0.5 \mathrm{M}$ sodium acetate (Fluka) at $\mathrm{pH} 4.0$ was added to $2 \mathrm{~mL}$ of milk for a final $\mathrm{pH}$ between 4.4 and 4.8. After centrifugation and filtration on a nylon filter (Cluzeau, France), the supernatant was injected on the HPLC system and the whey protein separated on a Hypersil C18 column and detected by fluorescence at excitation/emission wavelengths 290/330 $\mathrm{nm}$ on a fluorimeter (Thermo Separation Products, St. Michel sur Orge, France). The mobile phase consisted of solution A ( $0.1 \%$ trifluoroacetic acid; Prolabo, Fontenay sous Bois, France) and solution B ( $80 \%$ acetonitrile/20\% eluant $\mathrm{A}$ ), eluted at $1 \mathrm{~mL} / \mathrm{min}$, with $55 \%$ of solution A at initial conditions. The gradient program allowed reaching final conditions (80\% of solution B) in $35 \mathrm{~min}$, and returning to initial conditions (45\% solution B) in 10 min. The calibration used $\alpha$ - lactalbumin and $\beta$-lactoglobulin (Sigma), prepared in sodium acetate $(0.1 \mathrm{~mol} / \mathrm{L}, \mathrm{pH} 4.6)$. The analyses were carried out in duplicate.

The total concentration of proteins in the supernatant was measured according to the colorimetric method of Lowry et al. (1951), using external calibration with BSA (Euromedex, Souffelweyersheim, France). Measurements were done in triplicate.

\section{Furosine Analysis}

Furosine concentration was measured by HPLC-UV, according to a method adapted from Schleicher and Wieland (1981). Acid hydrolysis of milk proteins, firstly isolated by adding $7 \mathrm{~mL}$ of a mixture of water, ethanol, and dichloromethane (1:2:4) to $1 \mathrm{~mL}$ of milk, was performed in $7.8 \mathrm{~N} \mathrm{HCl}$ at $110^{\circ} \mathrm{C}$ for $18 \mathrm{~h}$. The hydrolysate was dried under vacuum (Speed Vac, Bioblock, Vanves, France), resuspended in water, filtered $(0.45-\mu \mathrm{m}$ nylon filter), and diluted before injection into the HPLC. The chromatographic system (Waters HPLC 610) was equipped with a Hypersil BDS C18 (Shandon) reversedphase (diameter $5 \mu \mathrm{m}$ ) column, $250 \mathrm{~mm} \times 4.6 \mathrm{~mm}$. The mobile phase was $5.6 \mathrm{mM}$ orthophosphoric acid and was eluted at $1 \mathrm{~mL} / \mathrm{min}$. Furosine was detected at 280 $\mathrm{nm}$. For each sample, the protein concentration of the injected solution was quantified using the fluorescamine probe according to the method of Yaylayan et al. (1992). The furosine content was expressed in milligrams per one hundred grams of protein. Each sample was prepared and analyzed in duplicate.

\section{Measurement of Advanced Maillard Products}

The fluorescence of advanced Maillard products was quantified in the milk fraction soluble at $\mathrm{pH} 4.6$ [obtained by adding 9 volumes of $0.1 \mathrm{M}$ sodium acetate buffer (adjusted to $\mathrm{pH} 4.6$ with acetic acid) to 1 volume of cow milk] according to the FAST method (BirlouezAragon et al., 1998). The fortified milk samples contained less protein, so the supernatant was prepared by adding $7.3 \mathrm{~mL}$ of buffer to $1 \mathrm{~mL}$ of milk to obtain similar protein content for all samples.

After filtering the supernatant through a $0.45-\mu \mathrm{m}$ pore nylon filter (Cluzeau) the filtrate fluorescence was measured in 4-face acryl cuvettes (Sarstedt, Mercey le Grand, France) on a Spex (Jobin-Yvon, Longjumeau, France) fluorimeter. Tryptophan fluorescence was measured at 290/340 nm and fluorescence of advanced Maillard products was measured at $330 / 420 \mathrm{~nm}$. The FAST index was calculated by dividing the fluorescence of advanced Maillard products by that of tryptophan and multiplying by 100. Each sample was prepared and analyzed in triplicate. 


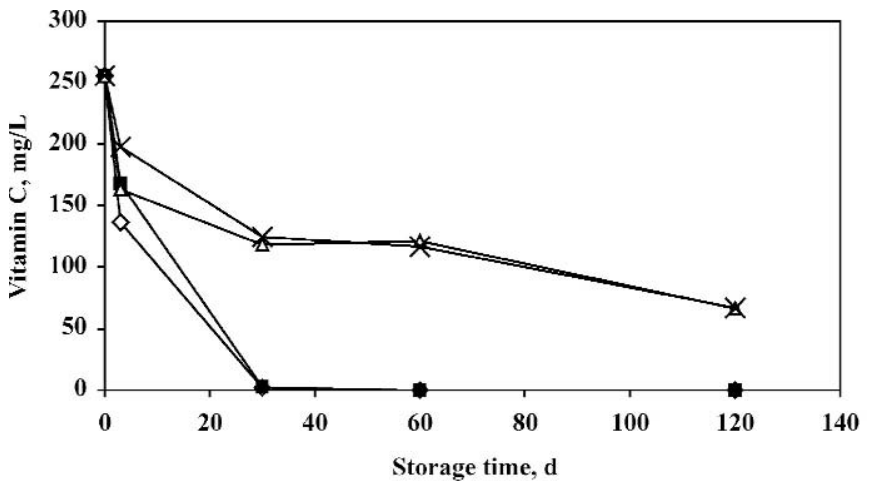

$\diamond$ FM-St-3L $\rightarrow-$ FM-UHT-3L $\triangle$ FM-St-6L $\rightarrow$ FM-UHT-6L

Figure 1. Evolution of vitamin $\mathrm{C}$ concentration as a function of storage. FM-St-3L = Fortified milk, in-bottle sterilized, stored in 3layered packaging; FM-UHT-3L = fortified milk, UHT sterilized, stored in 3-layered packaging; FM-St-6L = fortified milk, in-bottle sterilized, stored in 6-layered packaging; FM-UHT-6L = fortified milk, UHT sterilized, stored in 6-layered packaging.

The relative intensity of peptidic tryptophan fluorescence in the $\mathrm{pH} 4.6$-soluble fraction was measured by dividing the fluorescence by the protein concentration.

\section{Statistical Analyses}

Student $t$-tests (independent and paired) were applied using Microcal Origin software (version 5.0; Rockware, Inc., Golden, CO). The experimental designs as well as calculation of effects and interactions were calculated on Excel 5.0 (Microsoft, Redmond, WA). Two experimental designs with 3 factors and 2 levels were analyzed.

\section{RESULTS}

\section{Degradation of Vitamin C in Fortified Milk During Storage}

Figure 1 presents the vitamin $\mathrm{C}$ degradation curve in fortified milks as a function of storage time. The milk batch was fortified with $256 \mathrm{mg} / \mathrm{L}$ of vitamin C before sterilization treatment (value provided by the dairy plant). We observed a dramatic drop in the vitamin C content of samples stored in 3-layer bottles, and slow degradation in 6-layer bottles.

The first analysis of vitamin $\mathrm{C}$ was done $3 \mathrm{~d}$ after sterilization. At this stage, the loss in vitamin $\mathrm{C}$ was higher in in-bottle sterilized fortified milks than in UHT milks $(P<0.05)$. The effect of the packaging was already clear at this stage $(P<0.05)$. At longer storage times however, the effect of packaging was predominant, whereas no difference was observed between the sterilization technologies.

\section{Protein Denaturation as a Function of Storage}

The whey protein composition of the UHT milk acetate supernatant at $\mathrm{pH} 4.6$ is presented in Table 2. An important deformation of the eluted $\alpha$-lactalbumin and $\beta$-lactoglobulin peak impeded quantification in the sterilized samples. Similar problems occurred in UHT samples after 2 mo of storage, especially for $\beta$-lactoglobulin. The decrease in native whey proteins was particularly rapid for the first 2 mo of storage, especially for $\alpha$ lactalbumin. No effect of packaging was observed.

Figure 2 presents the percentage of protein denaturation, determined as the ratio (in \%) between the soluble protein content of the $\mathrm{pH} 4.6$-soluble fraction of milk and the total protein concentration as a function of storage. The denaturation rate was significantly higher in sterilized cow milk than in sterilized fortified milk regardless of storage time $\left(P<10^{-5}\right)$ and was higher in in-bottle sterilized milk than in UHT milk $(P<0.05)$, in agreement with the results for $\beta$-lactoglobulin and $\alpha$ lactalbumin. In contrast, the relative content of soluble proteins increased considerably for the first $2 \mathrm{mo}$ of storage $(P<0.05)$, before stabilizing.

Tryptophan fluorescence $(290 / 340 \mathrm{~nm})$ of the $\mathrm{pH} 4.6$ acetate fraction gives a rapid indication of the protein content in the supernatant (results not shown). It was well correlated to the whey protein concentration $\left(\mathrm{r}^{2}\right.$ between 0.82 and 0.95), despite obtaining a different regression line for sterilized and UHT fortified milk samples (Figure 3). When the tryptophan fluorescence was divided by the protein content to obtain the relative Trp fluorescence (Figure 4), a lower level was found in fortified milk samples compared with the other samples $(P<0.05)$. Moreover, a slight decrease was observed as a function of storage time. However, the nature of packaging had no significant influence on this marker except for UHT sterilized, fortified milks.

\section{The Maillard Reaction}

Evolution of the furosine content, indicator of the early step of the Maillard reaction. The evolution of furosine concentration in the different samples as a function of the storage time is shown in Figure 5. For a similar heat treatment (bottle sterilization), furosine was much higher in fortified milks than in cows' milk $(P<0.05)$. In addition, furosine concentration was significantly higher in in-bottle sterilized than in UHT milk $(P=0.008)$. Furosine concentration was almost stable for the first 2 mo of storage in in-bottle sterilized samples, whereas it increased significantly in the first 2 mo after UHT sterilization $(P<0.05)$. After 4 mo of storage, the content of furosine increased 1.7fold for in-bottle sterilized cows' milks, 2.4-fold for inbottle sterilized fortified milks, and 1.7-fold for UHT 
Table 2. Evolution of the concentration of $\alpha$-lactalbumin and $\beta$-lactoglobulin $(\mathrm{mg} / \mathrm{L})$ during storage of UHT fortified milks in 3- and 6-layered packaging. ${ }^{1}$

\begin{tabular}{lccccc}
\hline & \multicolumn{2}{c}{$\alpha$-lactalbumin } & & \multicolumn{2}{c}{$\beta$-lactoglobulin } \\
\cline { 2 - 3 } \cline { 5 - 6 } Storage time & FM-UHT-3L & FM-UHT-6L & & FM-UHT-3L & FM-UHT-6L \\
\hline 0 mo $(\mathrm{n}=2)$ & $268.47 \pm 6.45$ & $190.73 \pm 4.53$ & & $145.85 \pm 7.13$ & $168.32 \pm 6.63$ \\
2 mo $(\mathrm{n}=2)$ & $43.22 \pm 2.96$ & $61.88 \pm 5.45$ & & $99.58 \pm 3.43$ & $67.86 \pm 5.32$ \\
4 mo $(\mathrm{n}=2)$ & $32.34^{2}$ & $36.71 \pm 15.89$ & & ND $^{3}$ & ND \\
\hline
\end{tabular}

${ }^{1}$ FM-UHT-3L = fortified milk, UHT sterilized, stored in 3-layered packaging; FM-UHT-6L = fortified milk, UHT sterilized, stored in 6-layered packaging (mean values \pm SD).

${ }^{2} \mathrm{n}=1$.

${ }^{3} \mathrm{ND}=$ Not determined due to technical problems.

fortified milks. However, packaging had no significant effect on furosine content.

Evolution of the FAST index, as a marker of the advanced Maillard reaction. Table 3 indicates the FAST indices measured in the different samples throughout the storage time. The FAST index was 1.5 to 1.8 times higher after in-bottle sterilization than after UHT treatment of fortified milks. For the same heat treatment, the FAST index was significantly higher in fortified milk than in cows' milk, whatever the storage time $(P<0.05)$. The FAST index decreased significantly during storage in all milk samples $(P<$ $0.05)$.

\section{DISCUSSION}

The long storage time allowed by sterilization technologies is associated with a significant physicochemical evolution of the food product. Among the reactions developing upon storage, oxidation of vitamin $\mathrm{C}$ and polyunsaturated fatty acids, and protein glycation are the best documented. As these reactions can alter the quality and nutritional value of milk, it is important to monitor the impact of storage, particularly in foods with high nutritional relevance. Supplying the industry with rapid methods could be of particular interest for determining the optimal shelf life of commercial products. Milk is particularly prone to the Maillard reaction due to its high lactose and lysine content. Fortification with lactose, vitamin $\mathrm{C}$, polyunsaturated fatty acids, and iron, as is the case for fortified milk, further accelerates the reaction. We therefore aimed to evaluate the respective effect of the sterilization process, formulation, packaging, and storage time on a sensitive indicator of oxidation, the vitamin $\mathrm{C}$ content, and on 2 indicators of the early and advanced Maillard reaction (furosine and the FAST index).

Vitamin $\mathrm{C}$ is particularly prone to degradation during processing because of its high susceptibility to oxidation in the presence of oxygen and metal ions, and to degradation during heat treatment. We confirmed that the vitamin $\mathrm{C}$ added to fortified milks undergoes degradation during storage depending on the type of heat treatment and permeability of packaging to oxygen. The effect of sterilization methodology was only apparent during the first days of shelf life, whereas later in stor-

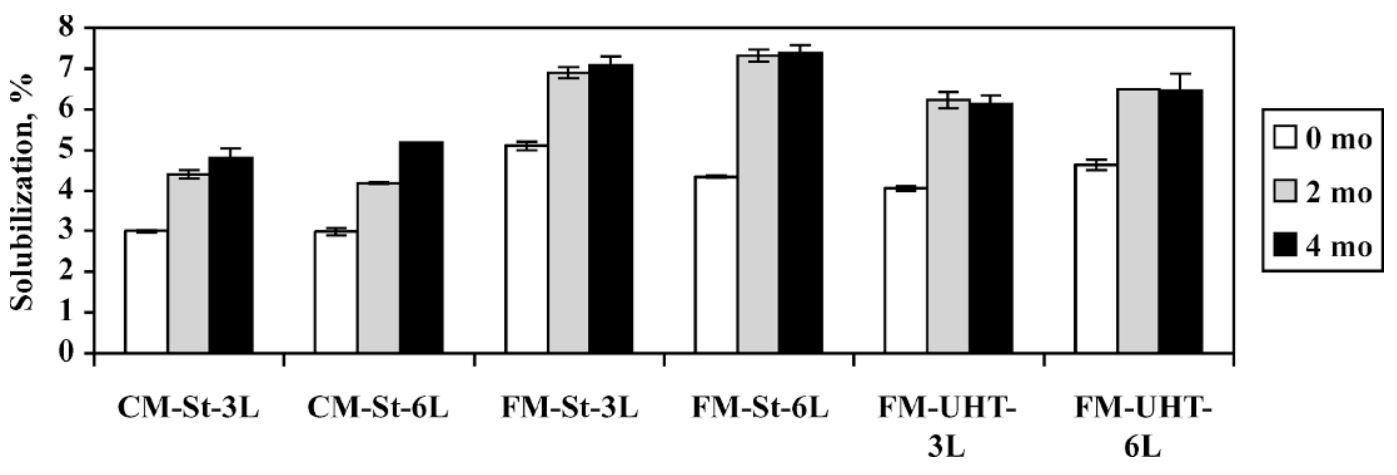

Figure 2. Increase in the $\mathrm{pH} 4.6$-soluble proteins (as \% of total proteins) as a function of storage time (mean \pm SD). CM-St-3L $=$ Cows' milk, in-bottle sterilized, stored in 3-layered packaging; CM-St-6L = cows' milk, in-bottle sterilized, stored in 6-layered packaging; FM-St$3 \mathrm{~L}=$ fortified milk, in-bottle sterilized, stored in 3-layered packaging; FM-St-6L = fortified milk, in-bottle sterilized, stored in 6-layered packaging; FM-UHT-3L = fortified milk, UHT sterilized, stored in 3-layered packaging; FM-UHT-6L = fortified milk, UHT sterilized, stored in 6-layered packaging. 


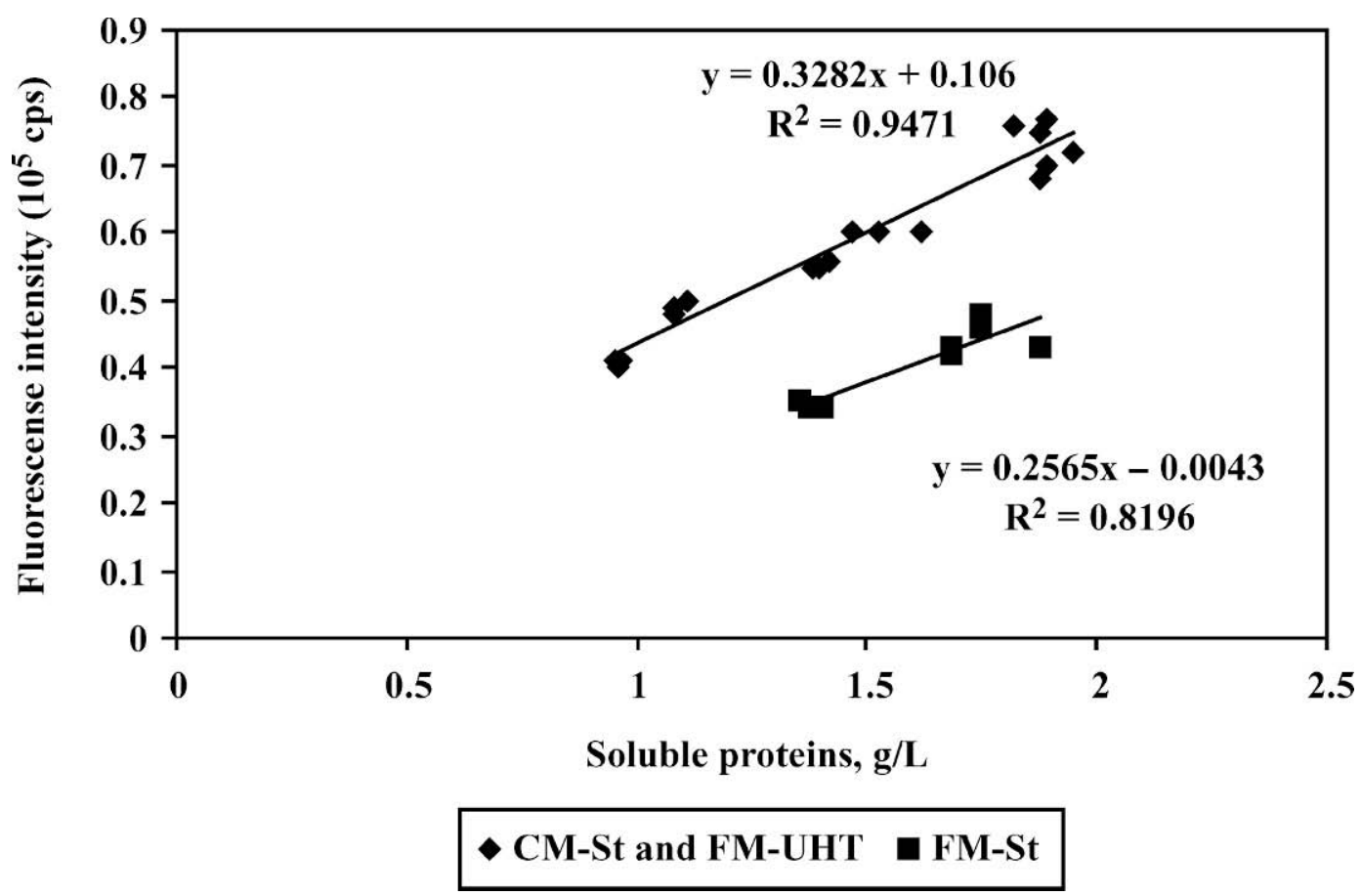

Figure 3. Correlation between soluble proteins and fluorescence of tryptophan in the $\mathrm{pH} 4.6$-soluble fraction. CM-St $=$ Cows' milk, inbottle sterilized; FM-UHT = fortified milk, UHT sterilized; FM-St = fortified milk, in-bottle sterilized.

age, the packaging permeability to oxygen became the main factor influencing vitamin $\mathrm{C}$ degradation in opaque polyethylene bottles. In these fortified milks, which were fortified with $256 \mathrm{mg} / \mathrm{L}$ of vitamin $\mathrm{C}$, the mean decrease in vitamin $\mathrm{C}$ content after $3 \mathrm{~d}$ storage was $35 \%$ of the initial value (Figure 1). After 1 mo of

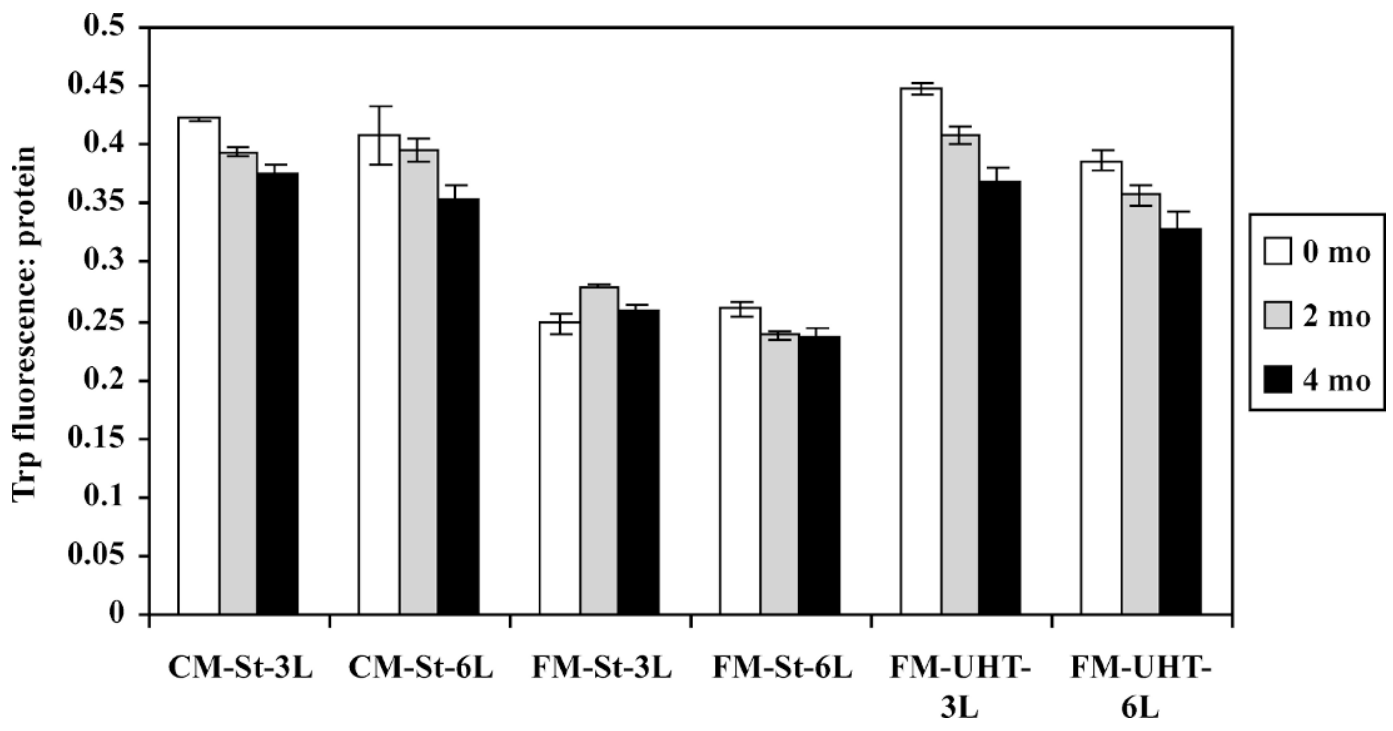

Figure 4. Evolution of tryptophan fluorescence-to-protein ratio as a function of storage time (mean \pm SD). CM-St-3L = Cows' milk, inbottle sterilized, stored in 3-layered packaging; CM-St-6L = cows' milk, in-bottle sterilized, stored in 6-layered packaging; FM-St-3L = fortified milk, in-bottle sterilized, stored in 3-layered packaging; FM-St-6L = fortified milk, in-bottle sterilized, stored in 6-layered packaging; FM-UHT-3L = fortified milk, UHT sterilized, stored in 3-layered packaging; FM-UHT-6L = fortified milk, UHT sterilized, stored in 6layered packaging. 


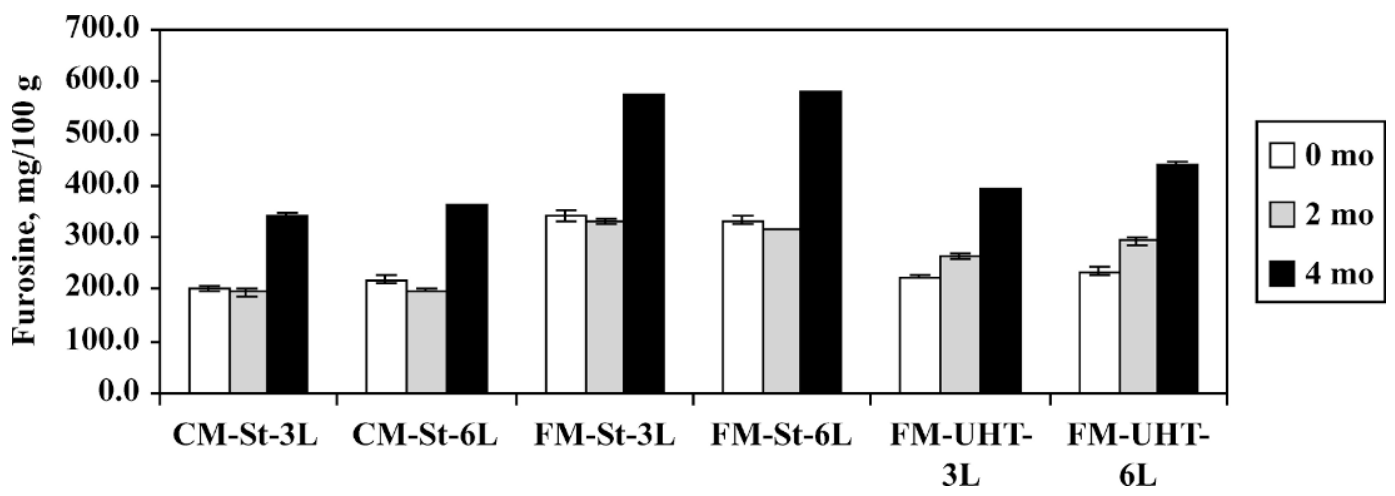

Figure 5. Evolution of the furosine concentration as a function of storage (mean \pm SD). CM-St-3L = Cows' milk, in-bottle sterilized, stored in 3-layered packaging; CM-St-6L = cows' milk, in-bottle sterilized, stored in 6-layered packaging; FM-St-3L = fortified milk, in-bottle sterilized, stored in 3-layered packaging; FM-St-6L = fortified milk, in-bottle sterilized, stored in 6-layered packaging; FM-UHT-3L = fortified milk, UHT sterilized, stored in 3-layered packaging; FM-UHT-6L = fortified milk, UHT sterilized, stored in 6-layered packaging.

storage at room temperature, the vitamin $\mathrm{C}$ degradation rate reached $99 \%$ in 3-layered and $51 \%$ in 6-layered packaging. After $4 \mathrm{mo}$, the concentration of vitamin $\mathrm{C}$ had fallen to $66 \mathrm{mg} / \mathrm{L}$ in 6-layered packaging, corresponding to $75 \%$ degradation. Many factors may explain this degradation: the sterilization heat treatment, the presence of iron, the oxygen in the headspace and dissolved in the milk, and perhaps, some atmospheric oxygen still reaching the milk through the packaging.

The high amount of vitamin $\mathrm{C}$ degradation products accumulating in the formulas after sterilization and storage should give rise to Maillard products (Leclère et al., 2002). Therefore, the development of Maillard reaction was investigated. Two indicators were measured, furosine (specific for lactose-derived reaction; Resmini and Pellegrino, 1991), and the global fluorescence, by means of the FAST method, sensitive to both lactosylation and ascorbylation (Leclère et al., 2002). Immediately after sterilization, higher furosine concentration and FAST index were found in fortified milk compared with cow's milk. These results, confirming previous data (Evangelisti et al., 1999; Birlouez-Aragon et al., 2004), are explained by the higher lactose content in formulas and by formation of many complex fluores- cent Maillard products, including those derived from ascorbate degradation products. In a previous paper (Birlouez-Aragon et al., 2002), it was shown that eliminating vitamin $\mathrm{C}$ from the vitamin mix added to the formula before sterilization allowed the FAST level to decrease to levels commonly measured in similarly processed regular cows' milk. The catalytic action of iron salts added to the formula could help explain the rapid oxidation of vitamin $\mathrm{C}$ and further reaction with proteins by ascorbylation giving rise to fluorescent Maillard products (Almaas et al., 1997; Bihel and BirlouezAragon, 1998).

However, during storage, no difference was observed in the FAST index between 3- 6-layered packaged samples despite the great difference in vitamin $\mathrm{C}$ degradation rate. We must then suppose that the slow vitamin $\mathrm{C}$ degradation rate during storage does not allow the production of fluorescent Maillard products, contrary to the rapid rate allowed by the sterilization heat treatment. Another possible explanation for the absence of ascorbylation products during storage could be the chelation of iron metals by the Maillard products previously formed during the sterilization process (Wagner et al., 2002).

Table 3. Fluorescence of advanced Maillard products and soluble tryptophan (FAST) indices as a function of storage time. ${ }^{1}$

\begin{tabular}{lllllll}
\hline Storage time & CM-St-3L & CM-St-6L & FM-St-3L & FM-St-6L & FM-UHT-3L & FM-UHT-6L \\
\hline 0 mo $(\mathrm{n}=3)$ & $248 \pm 4.5$ & $230 \pm 5.5$ & $267 \pm 0.9$ & $251 \pm 5.8$ & $149 \pm 0.7$ & $169 \pm 6.1$ \\
2 mo $(\mathrm{n}=3)$ & $190 \pm 0.9$ & $197 \pm 2.8$ & $203 \pm 0.4$ & $241 \pm 0.2$ & $131 \pm 0.1$ & $150 \pm 4.1$ \\
4 mo $(\mathrm{n}=3)$ & $165 \pm 0.0$ & $166 \pm 3.5$ & $198 \pm 1.5$ & $225 \pm 3.9$ & $136 \pm 3.1$ & $147 \pm 1.5$ \\
\hline
\end{tabular}

${ }^{1} \mathrm{CM}-\mathrm{St}-3 \mathrm{~L}=$ Cows' milk, in-bottle sterilized, stored in 3-layered packaging; CM-St-6L = cows' milk, inbottle sterilized, stored in 6-layered packaging; FM-St-3L = fortified milk, in-bottle sterilized, stored in 3layered packaging; FM-St-6L = fortified milk, in-bottle sterilized, stored in 6-layered packaging; FM-UHT$3 \mathrm{~L}=$ fortified milk, UHT sterilized, stored in 3-layered packaging; FM-UHT-6L = fortified milk, UHT sterilized, stored in 6-layered packaging (mean values $\pm \mathrm{SD}$ ). 
We further investigated the effect of heat treatment and storage on the lactose-derived Maillard reaction in the different milk samples. As expected, furosine was significantly (1.5 times) higher in the in-bottle sterilized samples than in UHT-treated, and those levels remained almost constant during the first 2 mo (Figure 5). However, a considerable increase occurred between 2 and 4 mo of storage, almost proportional to the initial level just after sterilization. Thus, the differences between sterilized and UHT samples were maintained. Similar increases in milk furosine and lactulose contents during storage has been widely described (Corzo et al., 1994; Ferrer et al., 2000a), indicating that the early Maillard reaction and lactose isomerization still develop during storage at ambient temperature.

The simple observation of the milk color in fortified milks, especially when in-bottle sterilized, was a first indication of the development of the advanced Maillard reaction in these conditions. As expected, the FAST index was higher in in-bottle sterilized than in UHT fortified milks (Table 3). However, it tended to decrease as a function of storage time. This can be explained by the insignificant development of the advanced Maillard reaction during storage at room temperature, whereas the relative Trp fluorescence of the proteins in the $\mathrm{pH}$ 4.6-soluble fraction decreases. Because the FAST index is a ratio between the fluorescence of advanced Maillard products and the Trp fluorescence (for correcting from the variable protein content of the $\mathrm{pH} 4.6$ supernatant) it therefore decreases upon storage (Birlouez-Aragon et al., 2002).

The protein composition of the $\mathrm{pH} 4.6$-acetate fraction was firstly dependent on the heat treatment applied to milk, with a more rapid denaturation of $\beta$-lactoglobulin than $\alpha$-lactalbumin in in-bottle sterilized than in UHT milk samples, confirming the higher thermosensitivity of the former (De Wit and Klarenbeek, 1984; Table 2). The strong lactosylation of the whey proteins after inbottle sterilization and during storage impeded the quantification of the chromatographic peak, because of important deformations (Corzo et al., 1994). Only liquid chromatography/mass spectrometry allows the detection and quantification of differently lactosylated whey protein fractions (Siciliano et al., 2000). The permeability of the packaging to oxygen had no effect on this phenomenon, suggesting that protein denaturation and glycation occurring during milk storage are oxygenindependent phenomena.

The quantification of the total soluble protein fraction is another way to monitor the denaturation process as a function of heat treatment and storage. The protein concentration of the acetate soluble fraction was lower in sterilized than in UHT formulas, confirming the higher protein denaturation in the former samples. It was higher in UHT formula than in UHT cows' milk, indicating a protective effect of the high lactose concentration in fortified milk, because of a higher ionic strength of the medium (Birlouez-Aragon et al., 1998). However, during storage, a rapid increase was observed during the first 2 mo, opposed to the continuous decrease in the specific native whey proteins (Figure 2). The simple measure of Trp fluorescence in the same fraction gave similar information, e.g., a level proportional to protein denaturation just after processing, and an increase as a function of storage time (data not shown). Hence, both parameters were correlated $\left(\mathrm{r}^{2}\right.$ between 0.82 and 0.95; Figure 3), even if not always directly associated. However, a lower Trp fluorescence per gram of protein was evidenced in sterilized formulas, for which the regression line between Trp fluorescence and protein content was below that obtained for UHT formulas and sterilized cow milk (Figure 3 ). This observation confirms previous results, where the lower Trp relative fluorescence could be associated with a lower Trp content in fortified milk samples (Birlouez-Aragon et al., 2004). In the present study, no direct analysis was done to confirm this. However, the decrease in Trp fluorescence-to-protein ratio as a function of storage, appearing concomitantly to the increase in proteins soluble at $\mathrm{pH} 4.6$, would be more consistent with hydrolysis of caseins during storage, as reported by Alkanhal (2000) and Garcia-Risco et al. (2002). The peptides generated by caseins, containing less Trp residues than whey proteins, could explain the decrease in the Trpto-protein ratio observed in this study.

\section{CONCLUSION}

From this study, we conclude that storage time has a very strong impact on the evolution of sterilized milk upon storage at ambient temperature. The early Maillard reaction slowly develops, resulting in a $50 \%$ increase in furosine in the sterilized formulas after 4 mo. Similarly, protein denaturation increases and some casein proteolysis occurs. Finally, oxidation-sensitive vitamin $\mathrm{C}$ is highly dependent on storage time and type of packaging, whether permeable to oxygen or not. Consequently, a radical modification of the milk composition occurs during storage, which aggravates the changes firstly induced by the sterilization heat treatment. Optimal quality would require UHT sterilization, packaging in 6-layered opaque bottles, and storage at a low temperature $\left(<20^{\circ} \mathrm{C}\right)$ or for a limited time $(<2 \mathrm{mo})$.

\section{REFERENCES}

Albala-Hurtado, S., M. T. Veciana-Nogues, M. Izquierdo-Pulido, and M. C. Vidal-Carou. 1997. Determination of free and total furfural 
compounds in infant formulas by high-performance liquid chromatography. J. Agric. Food Chem. 45:2128-2133.

Albala-Hurtado, S., M. T. Veciana-Nogues, A. Marine-Font, and M. C. Vidal-Carou. 1999. Progress of browning reactions during storage of liquid infant milks. J. Agric. Food Chem. 47:4033-4037.

Alkanhal, H. A. 2000. Suitability of methods used for the measurement of proteolysis in UHT milk. Aust. J. Dairy Technol. 55:148-152.

Almaas, R., T. Rootwelt, S. Oyasaeter, and O. D. Saugstad. 1997. Ascorbic acid enhances hydroxyl radical formation in iron-fortified infant cereals and infant formulas. Eur. J. Pediatr. 156:488-492.

Bihel, S., and I. Birlouez-Aragon. 1998. Inhibition of tryptophan oxidation in the presence of iron-vitamin $\mathrm{C}$ by bovine lactoferrin. Int. Dairy J. 8:637-641.

Birlouez-Aragon, I., V. Moreaux, M. Nicolas, and C. J. Ducauze. 1997. Effect of iron and lactose supplementation of milk on the Maillard reaction and tryptophan content. Food Addit. Contam. 4:381-388.

Birlouez-Aragon, I., M. Nicolas, A. Metais, N. Marchond, J. Grenier, and D. Calvo. 1998. A rapid fluorimetric method to estimate the heat treatment of liquid milk. Int. Dairy J. 8:771-777.

Birlouez-Aragon, I., M. Pischetsrieder, J. Leclere, F. J. Morales, K. Hasenkopf, R. Kientsch-Engel, C. J. Ducauze, and D. Rutledge. 2004. Assessment of protein glycation markers in infant formulas. Food Chem. 87:253-259.

Birlouez-Aragon, I., P. Sabat, and N. Gouti. 2002. A new method for discriminating milk heat treatment. Int. Dairy J. 12:59-67.

Bujard, E., and P. A. Finot. 1978. Mesure de la disponibilité et du blocage de la lysine dans les laits industriels. Ann. Nutr. Aliment. 32:291-305.

Corzo, N., R. Lopez-Fandino, T. Delgado, M. Ramos, and A. Olano. 1994. Changes in furosine and proteins of UHT-treated milks stored at high ambient temperature. Z. Lebensm. Unters. Forsch. 198:302-306.

De Wit, J. N., and G. Klarenbeek. 1984. Effect of various heat treatments on structure and solubility of whey proteins. J. Dairy Sci. 67:2701-2710

Drusch, S., V. Faist, and H. F. Erbersdobler. 1999. Determination of $\mathrm{N} \varepsilon$-carboxymethyl-lysine in milk products by a modified reversedphase HPLC method. Food Chem. 65:547-553.

Evangelisti, F., C. Calcagno, S. Nardi, and P. Zunin. 1999. Deterioration of protein fraction by Maillard reaction in dietetic milks. J. Dairy Res. 66:237-243.

Ferrer, E., A. Alegria, R. Farre, P. Abellan, and F. Romero. 2000a. Effects of thermal processing and storage on available lysine and furfural compounds content of infant formulas. J. Agric. Food Chem. 48:1817-1822.

Ferrer, E., A. Alegria, G. Courtois, and R. Farre. 2000b. High-performance liquid chromatographic determination of Maillard compounds in store-brand and name-brand ultra-high-temperaturetreated cows' milk. J. Chromatogr. A 881:599-606.

Finot, P. A., R. Deutsch, and E. Bujard. 1981. The extent of the Maillard reaction during the processing of milk. Prog. Food Nutr. Sci. 5:345-355.

Garcia-Risco, M. R., M. Villamiel, and R. Lopez-Fandino. 2002. Effect of homogenization on protein distribution and proteolysis during storage of indirectly heated UHT milk. Lait 82:589-599.

Gill, D. G., S. Vincent, and D. S. Segal. 1997. Follow-on formula in the prevention of iron deficiency: A multicentre study. Acta Paediatr. 86:683-689

Gillooly, M., J. D. Torrance, T. H. Bothwell, A. P. MacPhail, D. Derman, W. Mills, and F. Mayet. 1984. The relative effect of ascorbic acid on iron absorption from soy-based and milk-based infant formulas. Am. J. Clin. Nutr. 40:522-527.

Hallberg, L., L. Rossander-Hulten, M. Brune, and A. Gleerup. 1992. Bioavailability in man of iron in human milk and cow's milk in relation to their calcium contents. Pediatr. Res. 31:524-527.

Hewedy, M., C. Kiesner, K. Meissner, J. Hartkopf, and H. F. Erdersdobler. 1994. Effects of UHT heating of milk in an experimental plant on several indicators of heat treatment. J. Dairy Res. 61:305-309.

Hurrell, R. F. 1999. Preventing iron deficiency through food fortification. Nutr. Rev. 55:210-222.

Jelen, P., and W. Rattray. 1995. Thermal denaturation of whey proteins. Pages 66-85 in Heat-induced Changes in Milk. 2nd ed. P. F. Fox, ed. International Dairy Federation, Brussels, Belgium.

Kislinger, T., A. Humeny, C. C. Peich, X. Zhang, T. Niwa, M. Pischetsrieder, and C. M. Becker. 2003. Relative quantification of N(epsilon)-(carboxymethyl)lysine, imidazolone $\mathrm{A}$, and the Amadori product in glycated lysozyme by MALDI-TOF mass spectrometry. J. Agric. Food Chem. 51:51-57.

Korhonen, H., A. Pihlanto-Leppälä, P. Rantamäki, and T. Tupasella. 1998. Impact of processing on bioactive proteins and peptides. Trends Food Sci. Technol. 9:307-319.

Law, A. J., and J. Leaver. 2000. Effect of $\mathrm{pH}$ on the thermal denaturation of whey proteins in milk. J. Agric. Food Chem. 48:672-679.

Leclère, J., I. Birlouez-Aragon, and M. Méli. 2002. Fortification of milk with iron-ascorbate promotes lysine glycation and tryptophan oxidation. Food Chem. 76:491-499.

Lowry, O. H., N. J. Rosebrough, A. L. Farr, and R. J. Randall. 1951. Protein measurement with the Folin phenol reagent. J. Biol. Chem. 193:265-275.

Lynch, S. R., and J. R. Stoltzfus. 2003. Iron and Ascorbic Acid: Proposed Fortification Levels and Recommended Iron Compounds. J. Nutr. 133:2978S-2984S.

Nangpal, A., and H. Reuter. 1990. Formation of lactulose during UHT treatment of milk comparison between direct and indirect heating. Z. Milchwiss. Forsch. 42:31-41.

Pizzoferrato, L., P. Manzi, V. Vivanti, I. Nicolletti, C. Corradini, and E. Cogliandro. 1998. Maillard reaction in milk-based foods: Nutritional consequences. J. Food Prot. 61:235-239.

Puscasu, C., and I. Birlouez-Aragon. 2002. Intermediary and/or advanced Maillard product exhibit a prooxidant activity on Trp: In vitro study on $\alpha$-lactalbumin. Food Chem. 78:399-406.

Reddy, M. B., and M. Love. 1999. The impact of food processing on the nutritional quality of vitamins and minerals. Pages 99-106 in Impact of Processing on Food Safety. L. S. Jackson, M. G. Knize, and J. N. Morgan, ed. Kluwer Academic/Plenum Publishers, New York, NY.

Rerat, A., R. Calmes, P. Vaissade, and P. A. Finot. 2002. Nutritional and metabolic consequences of the early Maillard reaction of heattreated milk in the pig. Significance for man. Eur. J. Nutr. 41:1-11.

Resmini, P., and L. Pellegrino. 1991. Analysis of food heat damage by direct HPLC of furosine. Int. Chromatogr. Lab. 6:7-11.

Richards, E. L., and M. R. Chandrasekhara. 1960. Chemical changes in dried skim milk during storage. J. Dairy Res. 27:59-66.

Rowley, B. O., and T. Richardson. 1985. Protein-lipid interactions in concentrated infant formula. J. Dairy Sci. 68:3180-3188.

Schleicher, E., and O. H. Wieland. 1981. Specific quantification by HPLC of protein (lysine) bound glucose in human serum albumin and other glycosylated proteins. J. Clin. Chem. Clin. Biochem. 19:81-87.

Siciliano, R., B. Rega, A. Amoresano, and P. Pucci. 2000. Modern mass spectrometric methodologies in monitoring milk quality. Anal. Chem. 72:408-415.

Stadtman, E. R. 1991. Ascorbic acid and oxidative inactivation of proteins. Am. J. Clin. Nutr. 54:1125-1128.

Van Rentherghem, R., and J. De Block. 1996. Furosine in consumption milk and milk powders. Int. Dairy J. 6:371-382.

Villamiel, M., and P. de Jong. 2000. Influence of high-intensity ultrasound and heat treatment in continuous flow on fat, proteins, and native enzymes of milk. J. Agric. Food Chem. 48:472-478.

Wagner, K.-H., S. Derkits, M. Herr, W. Schuh, and I. Elmadfa. 2002. Antioxidative potential of melanoidins isolated from a roasted glucose-glycine mode. Food Chem. 78:375-382.

Yaylayan, V. A., A. Huyghues-Despointes, and A. Polydorides. 1992 A fluorescamine-based assay for the degree of glycation in BSA. Food Res. Int. 25:269-275. 